\title{
6.2 Chruschtschows Geheimrede auf dem XX. Parteitag der KPdSU
}

Der XX. Parteitag der KPdSU fand vom 14. bis zum 25. Februar 1956 statt. $^{384} \mathrm{Zu}$ dem ersten nach Stalins Tod veranstalteten Parteitag waren insgesamt 1424 Delegierte und Gäste aus 55 Ländern nach Moskau gekommen. Bereits zu Beginn distanzierte sich der Erste Sekretär des ZK der KPdSU, Nikita S. Chruschtschow, in einem mehrstündigen Rechenschaftsbericht von der außenpolitischen Generallinie der Vergangenheit und hob die Notwendigkeit der friedlichen Koexistenz mit den westlichen Staaten hervor. Doch erst am vorletzten Tag trug Chruschtschow in einem Geheimreferat eine grundsätzliche Kritik an Stalins Machtmissbrauch und Personenkult vor.

Die Parteidelegierten wurden zur ihrer Verblüffung aufgefordert, sich zu einer nicht öffentlichen Sitzung des Parteitages in den Kremlpalast einzufinden. Die auf dem Parteitag anwesenden ausländischen Gäste und Journalisten wurden nicht informiert. Zur Überraschung der Anwesenden wies Chruschtschow zu Beginn seiner Ausführungen darauf hin, dass bereits Lenin vor den Machtgelüsten Stalins gewarnt hatte. Nachdem er ausführlich auf die sogenannten Massenrepressalien aus der zweiten Hälfte der 1930er-Jahre einging, die unter anderem die politische und militärische Führungsschicht erbarmungslos dezimiert hatte, führte Chruschtschow aus:

Die Tatsachen beweisen, daß viele Mißbräuche auf Weisung Stalins erfolgten, ohne irgendwelche Normen der parteilichen und sowjetischen Gesetzlichkeit zu beachten. Stalin war ein sehr mißtrauischer Mensch mit krankhaftem Argwohn, wovon wir, die wir mit ihm arbeiteten, uns überzeugen konnten ... Der krankhafte Argwohn rief bei inm wahlloses Mißtrauen hervor, darunter auch im Verhältnis zu hervorragenden Parteifunktionären, die er seit vielen Jahren kannte. Überall, auf Schritt und Tritt, sah er »Feinde«, »Doppelzüngler« und »Spione«. Im Besitz einer unbeschränkten Macht tolerierte er grausame Willkür, erdrückte er die Menschen moralisch und physisch. Es entstand eine solche Situation, in der der Mensch seinen eigenen Willen nicht vorbringen konnte. Wenn Stalin sagte, der oder jener sei festzunehmen, so mußte man glauben, daß dies ein »Volksfeind « war ... Und welche Beweise wurden vorgelegt? Das Ceständnis der Verhafteten. Und die Untersuchungsrichter führten diese »Ceständnisse« herbei. Aber wie kann man einen Menschen dazu bringen, sich zu einem Verbrechen zu bekennen, das er nie begangen hat? Nur auf eine Art-durch Anwendung von physischen Methoden der Beeinflussung, durch Folter, Beraubung des Bewußtseins, des Verstandes, der menschlichen Würde. Auf diese Weise wurden die »Geständnisse« erreicht. ${ }^{385}$

Die Verurteilung von führenden Parteifunktionären in den Moskauer Schauprozessen beruhte hauptsächlich auf in der gleichen Weise erpressten Geständnissen und stand bereits vor der jeweiligen Gerichtsverhandlung fest. Nachdem Chruschtschow feststellte, dass von 139 Mitgliedern und Kandidaten des ZK, die auf dem XVII. Parteitag im Jahre 1934 gewählt worden waren, insgesamt 98 verhaftet und erschossen wurden, regte sich Empörung im Saal. Genauso als der Hinweis erfolgte, dass dasselbe Geschick auch die Mehrheit der Delegierten des XVII. Parteitages ereilte. Denn laut Chruschtschow wurden von den 1966 Delegierten weit mehr als die Hälfte, ge-

384 Das Folgende nach Kraushaar, Die Protest-Chronik 1949-1959, II, S. 1333 f.

385 Zit. n. ebd. 
nauer gesagt 1108 Personen, wegen »konterrevolutionärer Verbrechen« festgenommen. Nachdem Chruschtschow die näheren Umstände der Ermordung des Leningrader Parteisekretär Sergej M. Kirow am 1. Dezember 1934 ins Licht rückte, mit dem die »Massenrepressalien« Mitte der 1930er-Jahre in Gang kam, ging er daran, Stalin als den glorreichen Vaterlandsverteidiger zu entmystifizieren. Der angeblich geniale Feldherr habe mehrere ausdrückliche Warnungen vor dem Überfall der deutschen Wehrmacht in den Wind geschlagen, sodass keine Maßnahmen ergriffen wurden, um das Land zur Verteidigung vorzubereiten. Und nach dem schnellen Vormarsch der »Hitlertruppen« musste Stalin erst durch das ZK angehalten werden, Moskau fluchtartig zu verlassen.

Die anwesenden Delegierten forderte Chruschtschow dazu auf, den Personenkult »entschlossen ein für allemal« zu beseitigen. Mit Blick auf die erforderlichen Konsequenzen, die sich aus der Aufdeckung des stalinistischen Terrors ergaben, nannte er zum Abschluss seiner Geheimrede drei Punkte:

Erstens, auf bolschewistische Art den Personenkult zu verurteilen und auszurotten, der dem Geist des Marxismus-Leninismus fremd ist und mit den Prinzipien der Führung der Partei und den Normen des Parteilebens unvereinbar ist ... Zweitens, konsequent und ausdauernd die in den letzten Jahren vom Zentralkomitee der Partei unternommene Arbeit fortzusetzen, die gekennzeichnet ist durch genaueste Einhaltung der Leninschen Prinzipien der Führung der Partei in allen Parteiorganisationen, von oben und unten, und vor allem des Hauptprinzips, der Kollektivität der Leitung ... Drittens, die Leninschen Prinzipien der sowjetischen sozialistischen Demokratie voll wiederherzustellen, wie sie in der Verfassung der Sowjetunion ausgedrückt sind, die Willkür von Personen zu bekämpfen, die die Macht mißbrauchen. Bis zum Ende ist das Übel auszuräumen, das durch die Akte der Vergewaltigung der revolutionären sozialistischen Cesetzlichkeit bewirkt wurde und das sich über längere Zeit infolge der negativen Folgen des Personenkults angesammelt hat. ${ }^{386}$

Aufgrund eines Beschlusses des Präsidiums des ZK wurde über die Geheimrede Chruschtschows keine Diskussion zugelassen. Auf Vorschlag des Sitzungsleiters Nikolai A. Bulganin wurde indes von den Delegierten der einstimmige Beschluss ıÜber den Personenkult und seine Folgen gefasst, der in der sowjetischen Presse veröffentlicht wurde. Weiterhin wurde beschlossen, dass die Rede des Ersten Sekretärs des ZK der KPdSU an sämtliche Parteiorganisationen verschickt, allerdings nicht publiziert werden sollte. Kurz nach Sitzungsende wurden auch die Mitglieder der SED-Delegation, die in einem Gästehaus unterbracht waren, über den Inhalt der Geheimrede sehr genau in Kenntnis gesetzt. "Als sich Walter Ulbricht, Otto Grotewohl, Karl Schirdewan und Alfred Neumann«, so Wolfgang Kraushaar, »versammelt haben, holt ein hochrangiger Funktionär der KPdSU eine Kopie des Redemanuskriptes hervor und übersetzt eine Seite nach der anderen. Erst in den frühen Morgenstunden ziehen sich die SEDSpitzenfunktionäre sichtlich schockiert in ihre Schlafräume zurück. « ${ }^{387}$

Nachdem am 28. Februar 1953 die zentralen Thesen der chruschtschowschen Geheimrede im Zentralorgan der KPdSU, der Prawda, in einer allerdings abschwächten 
Form unter dem Titel Warum ist der Geist des Personenkultes dem Marxismus-Leninismus strikt fremd? erschien, wurde der vollständige Text am 5. Juni in der New York Times erstmalig veröffentlicht. Die als Sensation aufgefasste Geheimrede soll nach Angaben von Kraushaar aus einer polnischen Quelle stammen und, nachdem sie in den Besitz der CIA gelangte, an das State Department weitergegeben worden sein. Die gleiche Fassung bildete dann auch die Grundlage für die erste deutschsprachige Übersetzung, die von der Presseabteilung der US-amerikanischen Botschaft in der Zeitschrift OstProbleme kurz darauf veröffentlicht wurde. ${ }^{388}$

388 Ebd. Auf die zentralen politischen Motive, die Chruschtschow zu der Geheimrede veranlassten, gehe ich in Kap. IV.2.7 ein, wo auch die Rolle Chruschtschows während des stalinistischen Terrors zur Sprache gebracht wird. 


\title{
Der lonat
}

\section{EINE INTERNATIONALE ZEITSCHRIFT}

\author{
Der Westen \\ und die Zukunft Rußlands \\ mit Beiträgen von \\ Raymond Aron, Fedor Stepun, Ernst Reuter, \\ David J. Dallin. Max Beloff, Wilhelm liöpke
}

\section{Georg Glaser}

\section{Geheimnis und Gewalt}

\section{Bei Hitler zu Tisch}

BBC (II)

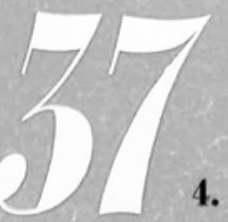

4. JAIIRGANG · I DV

Frontispiz der Ausgabe 37 (1951) 